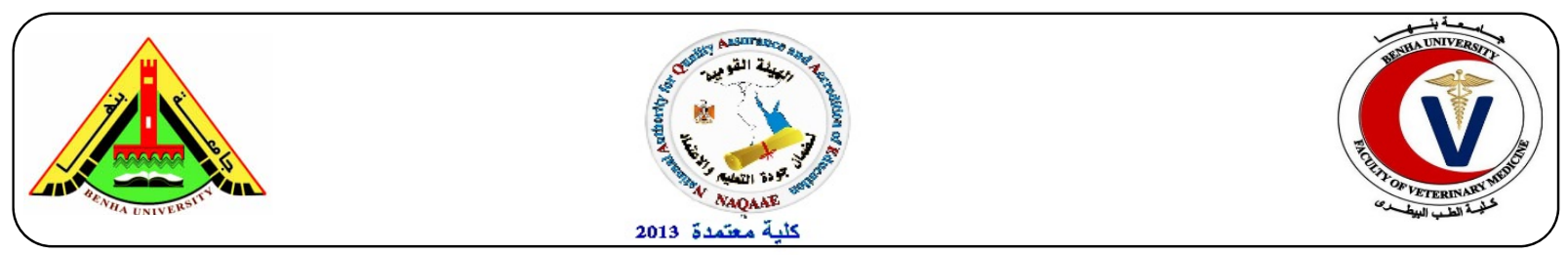

\title{
Histamine as a quality parameter in marine fish
}

\author{
Mohamed Ahmed Hassan ${ }^{1}$, Nessrine Zakareya Aelywah ${ }^{2}$, Fatma Hussien Ali ${ }^{2}$ \\ ${ }^{1}$ Food Hygiene Department, Faculty of Veterinary Medicine, Banha university. \\ ${ }^{2}$ Animal Health Research Institute, Tanta lab
}

\section{A B S T R ACT}

Histamine is a member of a group of compounds known as biogenic amines; Biogenic amines are biologically active compounds normally produced by decarboxylation of free amino acids and are present in a variety of foods, eg fish, fish products, meat, cheese and fermented foods. The presence of biogenic amines in these foods is an indicator of food spoilage. Histamine content is an essential quality parameter in sea food quality. In the present study a total of 90 random samples of fresh fishes represented by Pagrus, Barboni and Sardine (30 of each) were collected at different times from various fish markets in Gharbia governorate, Egypt, and examined for the presence of histamine by ELISA. The results revealed that $36.7 \%$ were acceptable and $63.3 \%$ non-acceptable for Sardine, $53.3 \%$ were acceptable while $46.7 \%$ nonacceptable for Barboni and $66.7 \%$ were acceptable and $33.3 \%$ non-acceptable for Pagrus.

Keywords: Histamine, ELISA, Marine fish.

\section{INTRODUCTION}

Fish is a great source of protein, vitamins, minerals, omega-3 fatty acids and a key nutrient for brain development. A well-balanced diet that includes a variety of fish and shellfish can contribute to heart health and children's proper growth and development (Jaclyn et al., 2010). Seafood may harbor a number of biological, chemical, and physical hazards, the most prevalent of which are biogenic amines (BAs) and bio toxins (chemical), pathogenic bacteria and viruses (biological), and metal inclusion (physical). BAs are low molecular weight organic bases with biological activity that are formed in foods by microbial decarboxylation of the corresponding amino acids or by transamination of aldehydes and ketones by amino acid transaminases (Zhai et al., 2012). Consumption of histamine can result in toxicological effects to consumers such as hypertension, headache, diarrhea, rash, and localized inflammation when ingested in extreme amounts, cardiac palpitation and even death in very severe cases (Rawles et al., 1996). Assessing biogenic amine presence is important not only from a toxicological point of view, but because these substances can be used as indicators of food degree of freshness or spoilage (Silva et al., 2013). The most important BAs, histamine, tyramine, tryptamine, putrescine, and cadaverine, are formed from free amino acids. They added that BAs accumulation in food requires the presence of microorganisms with amino acid decarboxylases and favorable conditions for their growth and decarboxylation activity. The consumption of high amount of BAs, above all histamine, can result in food borne poisoning which is a worldwide problem (Zarei et al., 2011). The most common fish associated with histamine fish poisoning are scombroid fish poisoning, the scombroid fish including tuna, mackerel, and non scombroid fish include sardine herring and anchovy (Flick et al., 2001).

The symptoms of HFP ranged from mild urticaria and oral allergy-like syndrome to lifethreatening cardiovascular reactions that can be mistaken for seafood allergy (Lionte, 2010). Histamine poisoning may not be caused to all the people consuming contaminated fish Thus, even if the same histamine-containing fish is ingested, some consumers may be poisoned and some may not (Tao et al., 2009). Further, the accumulation of biogenic amines in fish is involved in nitrosamine formation (known as carcinogens) (Yurchenko and Molder, 2006).

\section{MATERIAL AND METHODS}

\subsection{Collection of samples:}


A total of 90 random samples of fresh fishes represented by Pagrus, Barboni and Sardine (30 of each) were collected at different times from various fish markets in Gharbia governorate, Egypt.

Each sample was kept in a separated sterile plastic bag and preserved in an ice box then transferred to the laboratory under complete aseptic conditions without undue delay. The collected samples were subjected to the chemical examinations to evaluate their freshness through determination of proteolytic and lipolytic indices as well as their histamine contents.

\subsection{Determination of histamine by ELISA:}

\subsubsection{Sample preparation and acylation:}

Pipette $25 \mu \mathrm{L}$ of standards, $25 \mu \mathrm{L}$ of controls, $25 \mu \mathrm{L}$ of plasma samples, $10 \mu \mathrm{L}$ of urine samples, or $50 \mu \mathrm{L}$ of supernatant from the release test* into the respective wells of the Reaction Plate. Then add $25 \mu \mathrm{L}$ of Acylation Buffer to all wells; add $25 \mu \mathrm{L}$ of Acylation Reagent to all wells after that incubate for $45 \mathrm{~min}$ at RT $\left(20-25^{\circ} \mathrm{C}\right)$ on a shaker (approx. $600 \mathrm{rpm}$ ); add $200 \mu \mathrm{L}$ of distilled water to all wells. Then incubate for $15 \mathrm{~min}$. at RT $\left(20-25^{\circ} \mathrm{C}\right)$ on a shaker (approx. $600 \mathrm{rpm}$ ). Take $25 \mu \mathrm{L}$ of the prepared standards, controls, and samples for the Histamine ELISA. * For the release test the Histamine Release supplementary kit (available for purchase separately, cat. no. BA E-1100) has to be used.

\subsubsection{Histamine ELISA:}

Pipette $25 \mu \mathrm{L}$ of the acylated standards, controls, and samples into the appropriate wells of the Histamine Microtiter Strips. And pipette $100 \mu \mathrm{L}$ of the Histamine Antiserum into all wells and cover plate with Adhesive Foil. Incubate for 3 hours at RT $\left(20-25^{\circ} \mathrm{C}\right)$ on a shaker (approx. $600 \mathrm{rpm}$ ). Alternatively: shake the Histamine Microtiter Strips briefly by hand and incubate for $15-20$ hours at $2-8^{\circ} \mathrm{C}$. Then remove the foil. Discard or aspirate the contents of the wells and wash each well 4 times thoroughly with $300 \mu \mathrm{L}$ Wash Buffer. Blot dry by tapping the inverted plate on absorbent material. Pipette $100 \mu \mathrm{L}$ of the Enzyme Conjugate into all wells. Incubate for $30 \mathrm{~min}$ at RT $\left(20-25^{\circ} \mathrm{C}\right)$ on a shaker (approx. $600 \mathrm{rpm}$ ). Then discard or aspirate the contents of the wells and wash each well 4 times thoroughly with $300 \mu \mathrm{L}$ Wash Buffer. Blot dry by tapping the inverted plate on absorbent material. Pipette $100 \mu \mathrm{L}$ of the Substrate into all wells and incubate for $30 \mathrm{~min}$ at RT $\left(20-25^{\circ} \mathrm{C}\right)$ on a shaker $(600 \mathrm{rpm})$. Avoid exposure to direct sunlight. Add $100 \mu \mathrm{L}$ of the Stop Solution to each well and shake the microtiter plate to ensure a homogeneous distribution of the solution. Read the absorbance of the solution in the wells within 10 minutes, using a microplate reader set to $450 \mathrm{~nm}$ with a reference wavelength between $620 \mathrm{~nm}$ and $650 \mathrm{~nm}$.

\section{RESULTS}

It is evident from the results recorded in table (1) that the Histamine values in examined fish samples were varied from 5.4 to $65.5 \mathrm{mg} \%$ with an average of $36.87 \pm 1.53 \mathrm{mg} \%$ for Sardine; 3.9 to $61.5 \mathrm{mg} \%$ with an average $30.14 \pm 1.38 \mathrm{mg} \%$ for Barboni and 2.2 to $47.8 \mathrm{mg} \%$ with an average $18.36 \pm 0.95$ for Pagrus. The differences between the examined samples of different fish species were high significant $(P<0.01)$. Table $(2)$ revealed that $36.7 \%, 53.3 \%$ and $66.7 \%$ of the examined samples of sardine, Barboni and Pagrus were accepted, however, $63.3 \%, 46.7 \%$ and $33.3 \%$ of such samples were unaccepted, respectively.

\section{DISCUSSION}

Results were nearly similar to those obtained by (Humaid and Mamdoh, 2014) detected histamine formation in three fish species, Indian mackerel (Rastrelliger kanagurta),Goldstripe sardinella (Sardinella gibbosa) and Pink ear emperor (Lethrinus lentjan) were monitored during storage at $4^{\circ} \mathrm{C}$ for 144 hours and $25^{\circ} \mathrm{C}$ for 24 hours. Throughout the storage periods, Pink ear emperor had the lowest levels of histamine, $1.3 \pm 0.2 \mathrm{ppm}$ and $3.4 \pm 0.4 \mathrm{ppm}$ respectively, while in Indian mackerel and Gold stripe sardinella reached to $13.0 \pm 2.6 \mathrm{ppm}$, $7.0 \pm 0.2 \mathrm{ppm}$ at $4^{\circ} \mathrm{C}$ and $175.0 \pm 2.6 \mathrm{ppm}, 122.9 \pm 3.5$ ppm at $25^{\circ} \mathrm{C}$, respectively. While, higher results were obtained by Rajapaksha and Jayakody (2008) who found that fish at the landing sites had the lowest histamine level in a study done at landing sites in Sri Lanka (range $=0.223-9.4 \mathrm{ppm})$. Lower than those obtained by (Kim et al., 2009) who measured the histamine levels of Saury, Mackerel, Spanish mackerel and Amberjack stored at $25^{\circ} \mathrm{C}$ for 24 hours, were 2123.9, 1776.7, 189.9 and $36.6 \mathrm{ppm}$, respectively. Fish commonly implicated in histamine fish poisoning include both scombroid (mackerel, tuna and saury) and non- scombroid (sardine, anchovies, blue fish, as they contain large amount of free histadine (Lehane and Olley, 2000).

The hazardous level of histamine for human health has been suggested as $50 \mathrm{mg} \%$, although, low levels as $5 \mathrm{mg} \%$ have been reported in histamine poisoning (Huss et al., 2003). The content of biogenic amines differs according to species for example Scombridae family, such as tuna and bonito and Clupeidae family, such as 
Table (1): Statistical analytical results of histamine (mg \%) as quality index of spoilage in the examined samples of fish $(n=30)$.

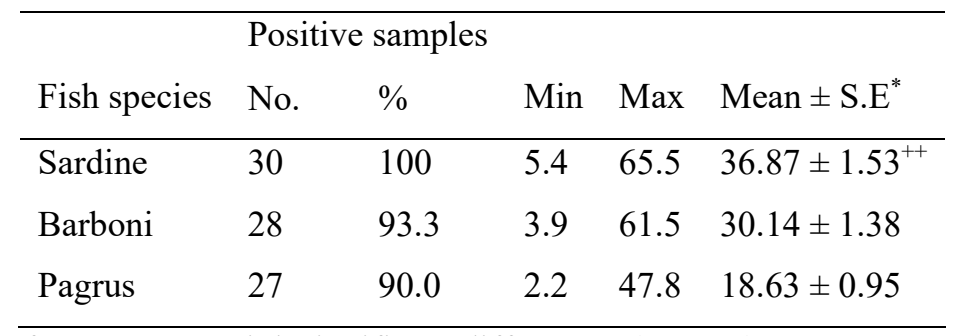

S.E $E^{*}=$ standard error of mean. $++=$ High significant differences $(P<0.01)$

Table (2): Acceptability of the examined samples of fish based on their levels of histamine ( $n=30)$.

\begin{tabular}{llllll}
\hline \multirow{2}{*}{ Fish Products } & MRL & \multicolumn{2}{c}{ Accepted samples } & \multicolumn{2}{c}{ Unaccepted samples } \\
& $(\mathrm{mg} \%)^{*}$ & No. & $\%$ & No. & $\%$ \\
\hline Sardine & 20 & 11 & 36.7 & 19 & 63.3 \\
Barboni & 20 & 16 & 53.3 & 14 & 46.7 \\
Pagrus & 20 & 20 & 66.7 & 10 & 33.3 \\
\hline
\end{tabular}

* Maximum Residual Limit stipulated by Egyptian Organization for Standardization "EOS" (2005).

sardines characterized by the presence of high levels of free histamine in their muscle, also according to the season of the year, genetics, environment, food, sex, physiological stage, storage period and sampled tissue (Lee et al., 2012). High levels of biogenic amines can be prevented by the application of good hygiene practices and proper temperature during handling, delivery and storage (Visciano et al., 2012). Preventive measures of freezing and cooling directly after death will prevent rapid development of enzyme histidine decarboxylase, because the hazard control is no possible after formation of enzyme (Anon, 2001). Biogenic amines can be used as quality index, once they are formed by bacterial activity and are resistant to thermal treatment, thus reflecting the quality of the raw material and hygienic conditions of food processing (Sagratini et al., 2012). Acceptability of examined fish samples based on their levels of histamine according to EOS (2005) the results revealed that $36.7 \%$ were acceptable and $63.3 \%$ non-acceptable for Sardine, $53.3 \%$ were acceptable while $46.7 \%$ non-acceptable for Barboni and $66.7 \%$ were acceptable and $33.3 \%$ non-acceptable for Pagrus. Unfortunately, unhygienic practices, in sufficient refrigeration cause increase susceptible to contamination by BAs-producing microorganisms and other spoilage bacteria (proteolytic and lipolytic) leading to rapid spoilage and outbreaks of fish poisoning.
As conclusion, histamine is the main marker for the evaluation of quality and safety of fish. Also, the application of good hygiene practices and proper temperatures during handling, delivery and storage reduce the bacterial growth and multiplication with further undesirable changes.

\section{REFERENCES}

Anon, A. 2001. Hand book of Fisheries statistics. Govt. of India, Ministry of Agriculture, New Delhi.

Egyptian Organization for Standardization "EOS" 2005. Reports related to No. 3494/2005 for chilled fish. Egyptian Standards, Ministry of Industry, Egypt.

Flick, J.G., Oria, P.M. and Douglas, L.2001. Potential hazards in cold-smoked fish: Biogenic Amines. Food Science Journal. 66: 1088-1099.

Huss H.H., Ababouch L. and Gram L. 2003. Assessment and management of seafood safety and quality, FAO Fisheries Technical Paper 444, Rome, 230 pp.

Jaclyn, M. C., Stacey, J. B. and Ashley, S. R. 2010. Omega-3 fatty acids and pregnancy. Obstetrics and Gynecology. 3: 163-171.

Kim, M. K., Mah, J. H. and Hwang, H. J.2009. Biogenic amine formation and bacterial contribution in fish, squid and shellfish. Food Chem. 116:87-95. 
Lee, Y., Kung, H., Lin, C., Hwang, C., Lin, C. and Tsai, Y. 2012. Histamine production by Enterobacteraerogenes in tuna dumpling stuffing at various storage temperatures. Food Chemistry. 131: 405-412.

Lehane, L. and Olley, J. 2000. Histamine fish poisoning revisited. International Journal of Food Microbiology. 58: 1-37.

Lionte, C. 2010. An unusual cause of hypotension and abnormal electrocardiogram (ECG) scombroid poisoning. Cent Eur J Med. 3:292-297.

Rajapaksha, S.G. and Jayakody, S. 2008. Nutrition challenges and innovative: A study on histamine levels of yellow fin tuna (Tunnus albacare) in different landing sites of Sri Lanka. Abstracts Scientific Sessions of the Fifth Food and Nutrition Symposium. Wayamba University of Sri Lanka, Sri Lanka.

Rawles, D.D., Flick, G.J. and Martin, R.Y. 1996. Biogenic amines in fish and shellfish. Adv. Food Nutr. Res. 39: 329-365.

Sagratini, G., Fernández-Frazón, M., Berardinis, F., Font, G., Vittori, S. and Mañes, J. 2012. Determination of eight un derivatised biogenic amines in fish by solid phase extraction and liquid chromatography- tandem mass spectrometry. Food Chemistry, 132: 537-543.

Silva, V. L.M., Lázaro de La Torre, C. A., Mársico, E. T., Mano, S. B. and Conte-Junior, C. A.2013. Aminas biogênicas como indicadores de qualidade de salames e produtos cárneosfermentados. Enciclopédia Biosfera 9: 69-84.

Tao, Z.; Sato, M., Yamaguchi, T. and Nakano, T.2009. Formation and diffusion mechanism of histamine in the muscle of tuna fish. Food Control 20: 923-926.

Visciano, P., Schirona, M., Tofalo, R. and Suzzi, G. 2012. Biogenic amine in raw and processed sea food. Department of Food science, University of Teramo, Italy. Frontiers in MICROBIOLOGY. 10:33-89.

Yurchenko, S. and MÖlder, U. 2006. Volatile Nnitrosamines in various fish products. Food Chem., 96:325-333.

Zarei, M., Najafzadeh, H, Enayati, A. and Pashmforoush, M. 2011. Biogenic aminescontent of canned tuna fish marketed in Iran. American- Eurasian J. Toxicol. Sci. 3: 190-193.

Zhai, H., Yang, X., Li, L., Xia, G., Cen, J., Huang, H. and Hao, S. 2012. Biogenic amines in commercial fish and fish products sold in southern china. Food Control 25: 303-308. 